\title{
Clinical Reasoning: A 64-Year-Old Man With Multiple Cranial Neuropathies
}

Ariel Lefland, MD, Alan D. Proia, MD, PhD, and Suma Shah, MD

Neurology ${ }^{\circledR} 2021 ; 97:$ e215-e221. doi:10.1212/WNL.0000000000012081
Correspondence

Dr. Lefland

Ariel.Lefland@duke.edu

\section{Section 1}

A 48-year-old man with hypertension, hyperlipidemia, and hypothyroidism presented to an outside institution with progressive bilateral lower extremity numbness and weakness. Nerve conduction studies (NCS) suggested acquired demyelinating polyneuropathy. Right sural nerve biopsy revealed mild chronic neuropathy, axonal degeneration, demyelination, and remyelination. He received monthly IV immunoglobulin (IVIg) and mycophenolate mofetil for a year. Due to worsening symptoms in the setting of lengthened IVIg dosing intervals, repeat NCS were obtained and showed disease progression. Monthly IVIg infusions were resumed for 8 years, during which his clinical and electrophysiologic findings stabilized. Treatment was subsequently stopped, and he initially remained neurologically stable off therapy.

Two years after IVIg discontinuation, the patient developed dysphagia and bilateral facial numbness and weakness. Unenhanced brain MRI showed atrophy without other intracranial pathology. He was placed on steroids and repeat NCS showed chronic sensorimotor polyneuropathy with new demyelinating features.

Two months later, the patient developed right cranial nerve (CN) VI and bilateral CN V, VII, and XII palsies. Brain MRI was notable for bilateral trigeminal nerve enhancement (figure). $\mathrm{He}$ was diagnosed with chronic inflammatory demyelinating polyneuropathy (CIDP) with cranial neuropathies and discharged on a prednisone taper with plans to reinitiate IVIg.

The patient continued to decline and presented to our institution 1 month later. He noted lethargy, facial pain, and painful right arm weakness. Examination revealed right eye ptosis with inability to move the right eye from midline, decreased sensation to pinprick over the right face, complete right facial weakness, right greater than left proximal upper extremity weakness, and absent reflexes.

\section{Questions for Consideration:}

1. What is the localization for the patient's presentation?

2. What is your differential diagnosis?

\section{GO TO SECTION 2}



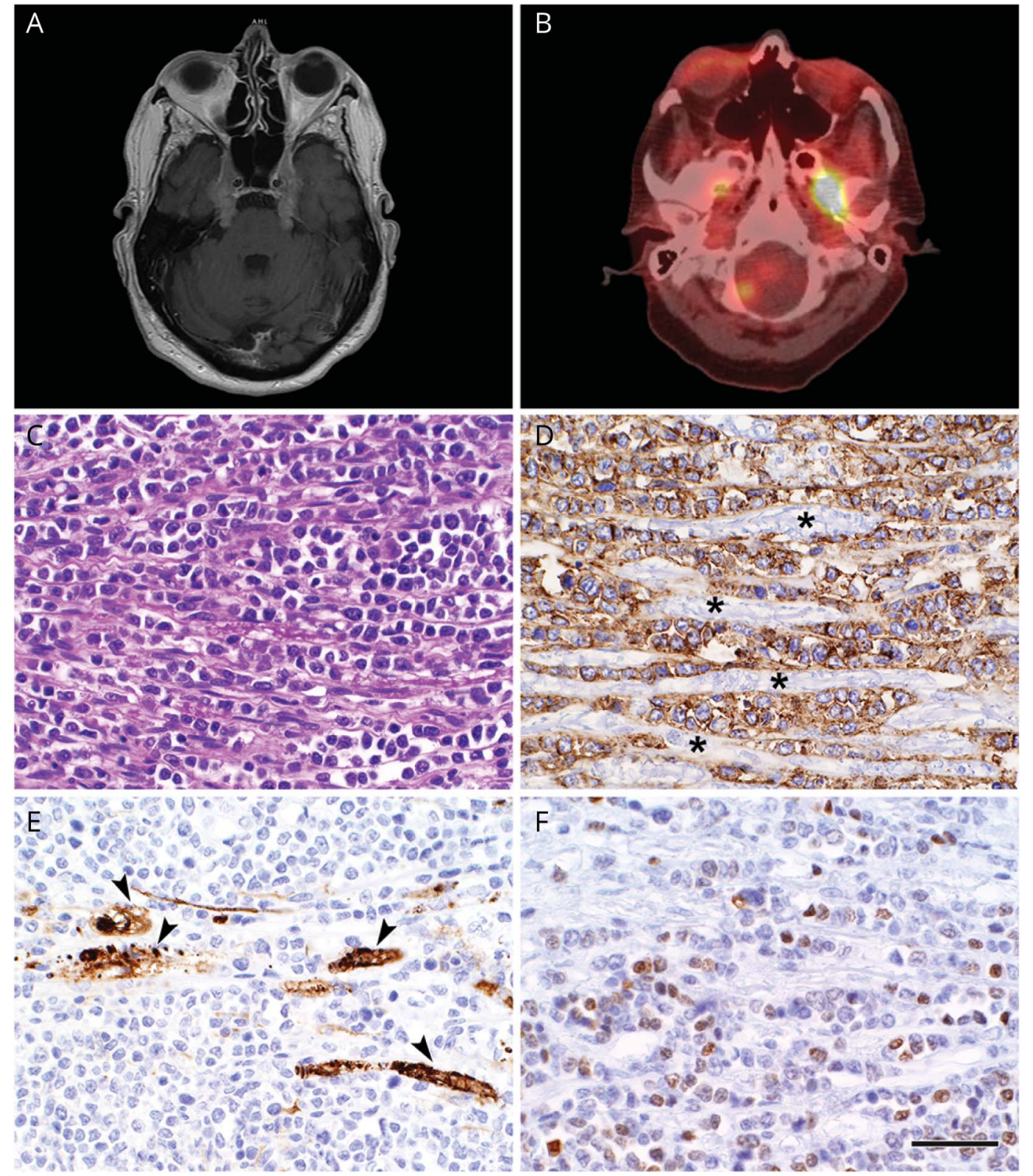

(A) Axial T1 postcontrast MRI shows symmetric nodular thickening and enhancement of the bilateral cisternal segments of cranial nerve (CN) V with extension into Meckel cave and involvement of the proximal segments of $\mathrm{V} 1, \mathrm{~V} 2$, and $\mathrm{V} 3$. There is greater involvement of the left $\mathrm{V} 3$ segment compared to the right. (B) Axial PET/CT demonstrates hypermetabolic FDG uptake corresponding to enhancing soft tissue thickening of the cisternal segments of cranial nerve $V$ extending into Meckel cave bilaterally. (C-F) Lymphomatous involvement of the right trigeminal nerve. (C) Large lymphoma cells massively infiltrated the right trigeminal nerve (hematoxylin \& eosin). (D) The tumor cells uniformly exhibited cell membrane expression of the B-cell marker CD20; the axons ( $*$ ) lacked immunoreactivity. (E) The lymphoma cells did not express CD10, while the axons (arrowheads) stained strongly positive. (F) Approximately 60\% of the lymphoma cells had nuclear expression of MUM1. The immunophenotype of the lymphoma was characteristic of the activated B-cell subtype, an aggressive form of diffuse large B-cell lymphoma. Magnification bar $=50 \mu \mathrm{m}$

\section{Section 2}

The patient presented with rapidly progressive cranial neuropathies in the setting of a reported diagnosis of CIDP. Localizing cranial neuropathies is challenging, as dysfunction can occur at any point along the nerves' course. Given this diagnostic complexity, a systematic approach to localization is helpful, such as considering anatomical locations: skull base and bone disorders, meningeal processes, brainstem syndromes, and peripheral nerve lesions. ${ }^{1}$ For each location, the differential diagnosis is broad, including infectious, inflammatory, traumatic, vascular, and malignant processes. ${ }^{2}$

Meningeal processes include carcinomatous and infectious meningitis secondary to Lyme disease (most commonly causing CN VII palsy and less commonly CN II, V, and VIII palsies), tuberculosis, neurosyphilis, fungi such as Cryptococcus neoformans, and viruses. ${ }^{1}$ Inflammatory meningitis 
Table Serum and CSF Studies

First admission

Second admission

Serum studies

Myasthenia gravis panel

Negative

GQ1B serum Ab

Negative

Paraneoplastic Ab

Serum protein electrophoresis

Serum immunofixation

Quantiferon gold

Cryptococcal Ag

Lyme PCR

Histoplasma Ag

Blastomyces Ab

Coccidioides Ab

Brucella Ab IgG/IgM

RPR

HIV1/HIV2 Ab and Ag

Toxoplasma Ab, IgG

Bartonella Ab

HSV PCR

VZV PCR

CMV PCR

Negative

Polyclonal increase in y-globulin

No monoclonal protein detected

Negative

Not detected

Negative

Negative

Negative

Negative

Negative

Nonreactive

Nonreactive

Negative

Negative

Not detected

Not detected

Not detected

CSF studies (reference ranges)

\begin{tabular}{|c|c|c|}
\hline Protein $(15-50 \mathrm{mg} / \mathrm{dL})$ & 402 & $>600$ \\
\hline Glucose, mg/dL & 21 & $<10$ \\
\hline Nucleated cells ( $0-5$ cells/ $\mu \mathrm{L})$ & 197 & 158 \\
\hline Percent lymphocytes (40\%-80\%) & $78 \%$ & $69 \%$ \\
\hline Percent variant lymphocytes & $7 \%$ & $19 \%$ \\
\hline Percent monocytes (15\%-45\%) & $7 \%$ & $7 \%$ \\
\hline Red blood cell count ( 0 cells $/ \mu \mathrm{L}$ ) & 1 & 1 \\
\hline Cryptococcal Ag & Not detected & Not detected \\
\hline VZV PCR & Not detected & \\
\hline HHV6 PCR & & Not detected \\
\hline VDRL & Negative & \\
\hline Culture & No growth & No growth \\
\hline Fungal culture & No growth & No growth \\
\hline Mycobacterial culture & & No growth \\
\hline Cytology & $\begin{array}{l}\text { Increased, predominantly small, } \\
\text { mature lymphocytes present }\end{array}$ & Small round mature lymphocytes \\
\hline Leukemia phenotype & $\begin{array}{l}\text { No definitive monoclonal B-cell population; } \\
\text { no phenotypically abnormal T-cell population }\end{array}$ & No monoclonal T- or B-cells \\
\hline
\end{tabular}

Abbreviations: Ab = antibody; Ag = antigen; CMV = cytomegalovirus; GQ1b = ganglioside Q1b; HHV6 = human herpesvirus; HSV = herpes simplex virus; IgG = immunoglobulin G; IgM = immunoglobulin M; RPR = rapid plasma reagin; VDRL = venereal disease research laboratory; VZV = varicella-zoster virus. 
secondary to granulomatous diseases such as sarcoidosis most often involves CN II, VII, VIII, IX, and X, and can have a similar appearance on MRI to that of this patient. However, imaging in this case was suggestive of an infiltrative process, which would be atypical of sarcoidosis. ${ }^{2}$

A central localization to the brainstem would likely present with long tract signs. Involvement of specific CNs may suggest localization to the cavernous sinus, orbital apex, or cerebellopontine angle. Peripheral disorders include Guillain-Barré syndrome (GBS), CIDP, and amyloidosis. ${ }^{2}$

Neoplastic cranial neuropathies can localize to any of these structural categories and include paraneoplastic neuropathies and infiltration of peripheral nerves. ${ }^{3}$ Notably, lymphoma can cause paraneoplastic CIDP-mimicking syndrome and neurolymphomatosis, a direct invasion of peripheral neural structures. $^{4}$
Workup for progressive cranial neuropathies should include infectious serologies, lumbar puncture with cytology, MRI, and malignancy and monoclonal gammopathy screenings. Lumbar puncture was notable for 197 nucleated cells/ $\mu \mathrm{L}$ (78\% lymphocytes), glucose $21 \mathrm{mg} / \mathrm{dL}$, and protein $402 \mathrm{mg} / \mathrm{dL}$ without growth on cultures. Infectious workup was unrevealing (table). Repeat brain MRI revealed bilateral nodular thickening and enhancement of CNs V1-V3 extending into Meckel cave and enhancement of right CNs VII, VIII, IX, and X. Left CN IX and $\mathrm{X}$ showed subtle enhancement. PET/CT demonstrated hypermetabolic uptake in the cisternal segments of $\mathrm{CN} \mathrm{V}$ and right C5-C7 neural foramina (figure), concerning for a neoplastic vs inflammatory process. The patient was treated with plasmapheresis.

\section{Question for Consideration:}

1. Based on these results, what additional studies would you recommend for diagnostic evaluation?

\section{GO TO SECTION 3}




\section{Section 3}

The patient was discharged and shortly thereafter readmitted for hypoxic respiratory failure requiring intubation. Laryngoscopy showed bilateral vocal cord paralysis. Brain MRI demonstrated new enhancement of CN VI bilaterally and worsening enhancement and enlargement of right greater than left CNs IX and XI. Open CN V biopsy, which can be useful in cases of diagnostic uncertainty, was offered but declined by the patient's family. In keeping with the patient's wishes, he was extubated and placed on comfort measures only. The patient's autopsy ultimately revealed diffuse large B-cell lymphoma (DLBCL) of activated B-cell subtype involving bilateral CNs V, VI, IX, and X, spinal nerve roots of the thoracic cord and cauda equina, right and left femoral nerves, and extrascleral, intrascleral, and intraocular short and long posterior ciliary nerves consistent with primary neurolymphomatosis (figure). There was no lymphoma elsewhere.

\section{Questions for Consideration:}

1. What aspects of the patient's presentation are consistent with CIDP?

2. Which features are inconsistent with this diagnosis?

GO TO SECTION 4 


\section{Section 4}

Neurolymphomatosis can present a diagnostic challenge to clinicians as it can mimic both nonneoplastic and paraneoplastic neuropathies. The most common presentation of neurolymphomatosis involves painful polyneuropathy or polyradiculopathy, although isolated cranial neuropathy can be the presenting pattern in $20 \%$ of patients. ${ }^{5}$ Differentiating features suggestive of neurolymphomatosis as opposed to CIDP include pain, asymmetric or focal distribution of symptoms, and rapid progression. ${ }^{4}$ In a review of 32 cases of neuropathy in lymphoma, 5 out of 15 patients with pathologyor image-proven neurolymphomatosis met electrodiagnostic criteria of definite CIDP. In these patients, there was a notable focality of involvement atypical for CIDP. An initial positive response to immunomodulatory therapy can also lead to a misdiagnosis of neurolymphomatosis as CIDP; however, most patients with neurolymphomatosis ultimately decline despite immunosuppressive therapy. ${ }^{3}$ Lack of sustained response to treatment, as in our patient, may be the diagnostic clue that points towards neurolymphomatosis.

It is worth considering whether the patient's initial presentation represented the first signs of lymphomatous infiltration rather than CIDP. Although the mean survival from neurolymphomatosis diagnosis is about 10 months, there are case reports of patients with neuropathic symptoms for months to years preceding neurolymphomatosis diagnosis, suggesting the initial symptoms could have been related to an occult malignancy. ${ }^{5}$ Alternatively, lymphoma has been postulated to arise out of malignant degeneration of B-cell clones targeting peripheral neural structures, and this patient's initial relapsing-remitting course may have represented a premalignant stage. ${ }^{6}$ Paresis often accompanies the painful polyneuropathy of neurolymphomatosis associated with lumbosacral nerve, nerve root, or cauda equina involvement. Painless polyneuropathy is also a recognized neurolymphomatosis subtype, and several case reports have been published detailing examples of cases of neurolymphomatosis in which patients experienced acute weakness reminiscent of GBS. ${ }^{6}$ It has also been observed that diseases of autoimmune etiology occur with higher than expected frequency in patients with neurolymphomatosis, suggesting CIDP and neurolymphomatosis could coexist. ${ }^{5,6}$ This patient's diagnosis was further complicated by $\mathrm{CN}$ and bulbar involvement, which is exceedingly rare in CIDP and should prompt consideration of alternative diagnoses. ${ }^{7}$

\section{Discussion}

Neurolymphomatosis is a rare neurologic manifestation of a hematologic malignancy characterized by lymphomatous invasion of peripheral neural structures. ${ }^{3}$ It is most commonly associated with aggressive forms of lymphoma, primarily DLBCL. ${ }^{4}$ It is estimated to have a relative annual incidence of $3 \%$ in patients with newly diagnosed intermediate or high- grade non-Hodgkin lymphoma. ${ }^{5}$ As in our patient, it can be the sole site of lymphomatous involvement in patients without known malignancy. ${ }^{4}$

Diagnosis of neurolymphomatosis is ultimately established on the basis of clinical features, CSF cytology, and imaging studies and often requires histopathologic evidence of infiltrating neoplastic lymphocytes on nerve biopsy. ${ }^{5}$ In the case of our patient, multiple lumbar punctures for cytology did not reveal cells with malignant morphology. Case studies have shown an association between neurolymphomatosis and hypoglycorrhachia, which was seen in this patient. ${ }^{4}$ CSF cytology is positive in approximately $40 \%$ of patients, but only a minority of cases have been reported to have positive CSF cytology at initial diagnosis. ${ }^{4,8}$ Evaluation for neurolymphomatosis with nerve biopsy is the diagnostic gold standard but can show false negatives due to sampling error, even in the setting of widespread lymphomatous infiltration of peripheral nerves. ${ }^{8}$ The risk of nerve damage must also be weighed against the possible benefit of diagnostic confirmation. As with our patient, up to $50 \%$ of reported cases lack a diagnosis until autopsy. ${ }^{5}$

Advanced imaging techniques, including gadoliniumenhanced MRI and PET/CT, have emerged as powerful diagnostic tools in the workup of neurolymphomatosis, with recent reviews suggesting sensitivity of MRI and PET/CT approach of $80 \%$ and $90 \%$, respectively. ${ }^{9}$ The former provides increased anatomical detail and typically shows diffuse or nodular thickening and enhancement of affected nerves with increased signal on fluid-sensitive sequences, consistent with our patient's imaging. ${ }^{9}$ MRI can further be useful by guiding nerve biopsy. ${ }^{9}$ The latter is useful for demonstrating abnormalities in the nerve plexus or peripheral nerves in the extremities, characteristically exhibiting intense linear uptake. ${ }^{9}$

In patients with painful, asymmetric, or rapidly progressive neuropathy, multiple cranial neuropathies, or electrodiagnostic data concerning for CIDP, who do not respond to immunomodulatory therapies, further workup for neurolymphomatosis with CSF cytology, MRI, PET/CT, and nerve biopsy should be considered. Enlargement of nerve roots or contrast enhancement on MRI should suggest lymphomatous infiltration in this clinical context. The presence of demyelinating features on EMG should not detract from a diagnosis of neurolymphomatosis. ${ }^{10}$ This patient's presentation highlights the diagnostic challenge of evaluating multiple cranial neuropathies in someone with a preexisting autoimmune neurologic disorder. It is important to keep a broad differential in patients who present with uncommon presentations of both common and uncommon disorders.

\section{Study Funding}

No targeted funding reported.

\section{Disclosure}

The authors report no disclosures. Go to Neurology.org/N for full disclosures. 


\section{Appendix Authors}

\begin{tabular}{lll}
\hline Name & Location & Contribution \\
\hline $\begin{array}{l}\text { Ariel } \\
\text { Lefland, MD }\end{array}$ & $\begin{array}{l}\text { Duke University } \\
\text { Medical Center, } \\
\text { Durham, NC }\end{array}$ & $\begin{array}{l}\text { Drafting and approval of } \\
\text { manuscript }\end{array}$ \\
\hline $\begin{array}{l}\text { Alan D. } \\
\text { Proia, MD, } \\
\text { PhD }\end{array}$ & $\begin{array}{l}\text { Duke University } \\
\text { Medical Center, } \\
\text { Durham; Campbell } \\
\text { of Osteopathic } \\
\text { Medicine, } \\
\text { Lillington, NC }\end{array}$ & $\begin{array}{l}\text { Drafting, critical revision, and } \\
\text { approval of manuscript }\end{array}$ \\
\hline Suma Shah, & $\begin{array}{l}\text { Duke University Medical } \\
\text { Center, Durham, NC }\end{array}$ & $\begin{array}{l}\text { Drafting, critical } \\
\text { revision, and approval } \\
\text { MD }\end{array}$ \\
\end{tabular}

\section{References}

1. Carroll CG, Campbell WW. Multiple cranial neuropathies. Semin Neurol. 2009;29:53-65. issue 1

2. Beal MF. Multiple cranial-nerve palsies: a diagnostic challenge. N Engl J Med. 1990; 322(1):461-463.

3. Tomita M, Koike H, Kawagashira Y, et al. Clinicopathological features of neuropathy associated with lymphoma. Brain. 2013;136(Pt 8):2563-2578.

4. Grisariu S, Avni B, Batchelor TT, et al. Neurolymphomatosis: an international primary CNS lymphoma collaborative group report. Blood. 2010;115(24):5005-5011.

5. Baehring JM, Batchelor TT. Diagnosis and management of neurolymphomatosis. Cancer J. 2012;18(5):463-468.

6. Baehring JM, Damek D, Martin EC, Betensky RA, Hochberg FH. Neurolymphomatosis. Neuro Oncol. 2003;5(2):104-115.

7. Reynolds J, Sachs G, Stavros K. Chronic inflammatory demyelinating polyradiculoneuropathy (CIDP): clinical features, diagnosis, and current treatment strategies. R I Med J. 2016;99(12):32-35.

8. Kim JH, Jang JH, Koh SB. A case of neurolymphomatosis involving cranial nerves: MRI and fusion PET-CT findings. J Neurooncol. 2006;80(2):209-210.

9. Lim AT, Clucas D, Khoo C, Parameswaran BK, Lau E. Neurolymphomatosis: MRI and (18) FDG-PET features. J Med Imaging Radiat Oncol. 2016;60(1):92-95.

10. Kelly JJ, Karcher DS. Lymphoma and peripheral neuropathy: a clinical review. Muscle Nerve. 2005;31(3):301-313. 


\title{
Neurology
}

\section{Clinical Reasoning: A 64-Year-Old Man With Multiple Cranial Neuropathies}

\author{
Ariel Lefland, Alan D. Proia and Suma Shah
}

Neurology 2021;97;e215-e221 Published Online before print April 23, 2021

DOI 10.1212/WNL.0000000000012081

\section{This information is current as of April 23, 2021}

\section{Updated Information \& Services}

References

Subspecialty Collections

Permissions \& Licensing

Reprints including high resolution figures, can be found at: http://n.neurology.org/content/97/2/e215.full

This article cites 10 articles, 1 of which you can access for free at: http://n.neurology.org/content/97/2/e215.full\#ref-list-1

This article, along with others on similar topics, appears in the following collection(s):

All Clinical Neurology

http://n.neurology.org/cgi/collection/all_clinical_neurology Autoimmune diseases

http://n.neurology.org/cgi/collection/autoimmune_diseases Chronic inflammatory demyelinating polyneuropathy http://n.neurology.org/cgi/collection/chronic_inflammatory_demyelinat ing_polyneuropathy

Cranial neuropathy

http://n.neurology.org/cgi/collection/cranial_neuropathy

Information about reproducing this article in parts (figures,tables) or in its entirety can be found online at:

http://www.neurology.org/about/about_the_journal\#permissions

Information about ordering reprints can be found online:

http://n.neurology.org/subscribers/advertise

Neurology ${ }^{\circledR}$ is the official journal of the American Academy of Neurology. Published continuously since 1951, it is now a weekly with 48 issues per year. Copyright () 2021 American Academy of Neurology. All rights reserved. Print ISSN: 0028-3878. Online ISSN: 1526-632X.

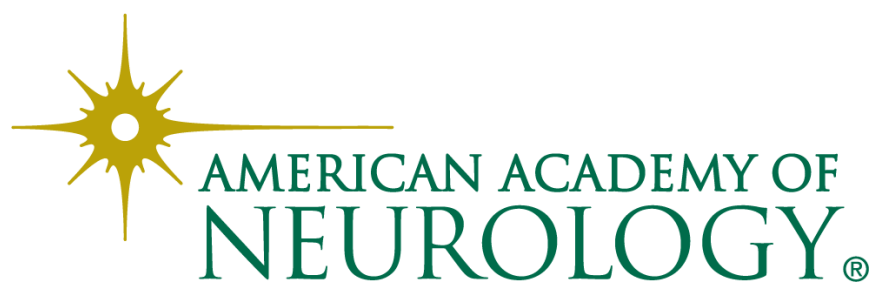

